\title{
Resilience in the developing world benefits
}

\section{everyone}

\author{
We need a modern-day Marshall Plan to build climate resilience in the developing world. It is doable if, for each \\ dollar spent reaching net zero, we spend an additional 25 cents on building resilience.
}

\author{
Tim Palmer
}

egardless of whether you approved of last year's school strikes or the disruption to city life caused by Extinction Rebellion's demonstrations, there is no doubt these actions put climate change back up the global policy agenda. And for good reason - according to both the World Economic Forum 2019 and 2020 reports ${ }^{1}$, extreme weather events and climate action failure are the top two risks facing the world. Of course, these risks are not unrelated. Indeed, notwithstanding the urgency of moving to net zero by mid-century, it's time to refocus efforts on the parallel need to build resilience to the changing nature of weather extremes, particularly in the developing world where population growth is largest and society is most vulnerable. To do justice to this problem, I argue that we need to think in terms of a modern-day Marshall Plan.

The Marshall Plan was an initiative where significant US funding helped rebuild the European economy shortly after the end of World War II. For some, it was an altruistic gesture at a time when Europe was on its knees. For others, it was motivated by self-interest: the perceived need to prevent the spread of communism. A Marshall Plan to build climate resilience in the developing world can also be motivated in different ways. For some, it can be seen as an ethical gesture, recognizing the impact developed-nation carbon emissions have had, and will continue to have, on the poor and vulnerable ${ }^{2}$. However, irrespective of ethics, the drivers of migration away from the tropics and subtropics, already reaching problematic levels in both Europe and the US, may increase dramatically if we allow the quality of life to decline further due to the effects of a warming climate. In particular, increasing extremes of climate, whether in terms of enhanced periods of severe heat stress from a combination of increasing temperature and humidity ${ }^{3}$, more intense tropical cyclones and associated storm surges ${ }^{4}$, or longer-lived drought ${ }^{5}$, are all likely to produce the reduction in economic productivity and standards

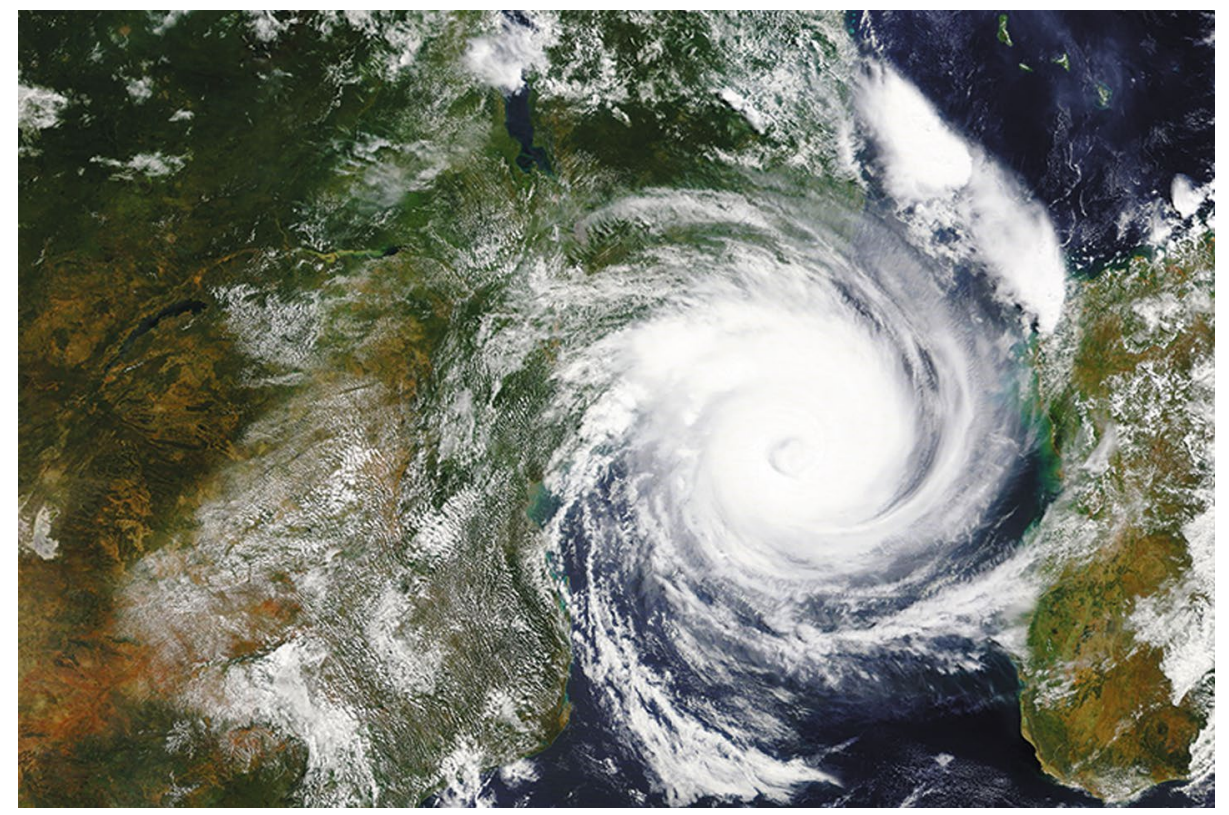

Fig. 1 | Cyclone Idai as it hit Mozambique. In order to become more resilient to the increasingly severe nature of tropical cyclones, a number of factors need to be improved substantially: better forecasts and better use of forecasts for taking pre-emptive action, better infrastructure to cope with the deadly nature of the winds as well as associated storm surges and restoration of natural ecosystems that can help protect against some of the storms' worst effects. Credit: Claudia Weinmann / Alamy Stock Photo

of living that could force mass poleward migration. For those living in regions targeted by such migrations, a climate Marshall plan could indeed be justified by raw self-interest.

There are three aspects to building climate resilience: engineering solutions, nature-based solutions and disaster risk reduction.

The first, well reported elsewhere ${ }^{6}$, concerns a variety of different types of infrastructure such as the development of solar-powered air conditioning units for buildings in regions where wet-bulb temperatures are projected to reach levels where the human body can no longer lose heat $^{7,8}$, the provision of solar-powered desalination units in drought-prone areas with access to sea water ${ }^{9}$, bigger storm sewers in regions projected to suffer more intense flooding ${ }^{10}$, buildings that are better able to withstand exceptional wind strengths, and better protection against stronger storm surges in those regions at risk from increasingly intense tropical cyclones ${ }^{11}$. Being able to target resources effectively requires improved knowledge about these regional extremes of climate change. This requires significant improvements to the spatial and temporal resolution of global climate models ${ }^{12}$.

Nature-based solutions ${ }^{13-15}$ involve actions that work with and enhance natural habitats. Numerous examples of nature-based solutions exist. Afforestation, reforestation and conservation of existing natural forests can reduce soil erosion and flood risk (while increasing carbon sequestration). Restoring salt marshes and natural wetlands help protect coastal 
societies against storm surges. Increasing urban green spaces reduces the urban heat island effect. As well as using natural ecosystems to protect local societies against the worst effects of extreme weather, these nature-based solutions have multiple co-benefits and, for example, can help arrest the dramatic loss of biodiversity reported by Intergovernmental Science-Policy Platform on Biodiversity and Ecosystem Services $(\text { IPBES })^{16}$.

Developing our early-warning systems so as to be better prepared for individual extreme events is an important part of the programme to improve climate resilience. The UN Sendai Framework for Disaster Risk Reduction calls for a substantial decrease in mortality due to natural disasters, some $90 \%$ of which are associated with extreme weather. The thousands of fatalities caused by recent intense tropical cyclones (for example, Idai, which devastated parts of Mozambique, Zimbabwe and Malawi in 2019 (Fig. 1)) are a reminder of how deadly extreme weather events are in the tropics. Here there is a need to improve our ability to predict severe weather many days ahead (to allow emergency services to become more proactive in providing aid): this can be achieved through investment in exascale computing technology dedicated to weather and climate prediction and advanced artificial intelligence methods to downscale to the local scale ${ }^{17}$. However, there also needs to be better means of communicating levels of danger to society. For example, in Mozambique it was reported that some would not leave their dwellings, even though they were vulnerable to the storm surge associated with the predicted cyclones, because they feared getting burgled and losing their life possessions. Developing forecast-based financing systems that provide funding triggered by forecasts of extreme events could help alleviate such a fear ${ }^{18}$.

How much will all this cost? According to the 2016 United Nations Environment Programme's (UNEP) finance gap report ${ }^{19}$, the costs of climate adaptation are likely to be somewhere between US $\$ 140$ billion to US $\$ 300$ billion per year by 2030 , increasing to US $\$ 280$ billion to US $\$ 500$ billion by 2050 .
This is broadly consistent with figures from the World Bank report ${ }^{20}$ that the amount of investment to enable countries to meet sustainable development goals - such as universal access to water, sanitation and electricity, food security and protection against floods - may require investment on new infrastructure anywhere from 2 to $8 \%$ of the GDP of low-to-middle income countries. Let us assume that the climate adaptation needs of these countries is half of these average costs (recovering from COVID-19 is a topical example of a non-climate-related cost) - say around 2\% of GDP - and that the developed world funds approximately half. The ratio of GDP between low- and lower-middle-income countries and high-income countries is about 0.6. Then, in round figures, an investment corresponding to $0.5 \%$ of developed countries' GDP (about $\$ 250$ billion per year, consistent with the UNEP estimate above) will be needed to fund a programme with the ambition of a latter-day Marshall Plan.

This is a lot of money. However, the amount needs to be put into context. The UK government has announced that it will reduce the UK's carbon emissions to net zero by 2050 . It is widely believed that such a commitment will cost around $£ 50$ billion a year, or $2 \%$ of UK GDP. If we assume that the cost of such mitigation actions in other developed countries will similarly be $2 \%$ of GDP, then for every dollar that a developed country spends on reaching net zero by 2050 , it should spend a second quarter of a dollar on building climate resilience in the developing world. Of course, a single country acting on its own in this area would have little impact. However, a leadership role taken by a country such as the UK will inspire other developed economies to follow suit.

At the Paris conference, developed countries did in fact commit to mobilize finance for the purposes of climate adaptation at the level of US\$100 billion a year. However, none of the agreements were binding. Where are we now? The Adaptation Fund is an international fund, set up under the Kyoto Protocol of the UN Convention on Climate Change, that finances adaptation projects in developing countries. However, according to the fund's own records, new pledges in the last year corresponded to about US\$129 million, up from US\$96 million the year before. Essentially, we are an order of magnitude short of the commitments made in Paris, and substantially more that an order of magnitude short of what may really be needed to make a difference, according to World Bank and UNEP estimates.

Whether motivated by altruism or self-interest, the UN Climate Change Conference (UNFCCC Conference of the Parties COP26 now moved to 2021) provides an ideal opportunity for the developed world to reaffirm the importance of climate adaptation and to take a lead and commit itself to such a Climate Marshall Plan.

\section{Tim Palmer(D) $\bowtie$}

Department of Physics, University of Oxford, Oxford,

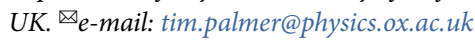

Published online: 27 August 2020 https://doi.org/10.1038/s41558-020-0888-8

References

1. World Economic Forum. The Global Risks Report (2020).

2. Barbier, E. B. \& Hochard, J. P. Rev. Env. Econ. Policy 12, 26-47 (2018).

3. Li, D., Yuan, J. \& Kopp, R. Environ. Res. Lett. 15, 6 (2020).

4. Knutson, T. et al. Bull. Am. Meteor. Soc. 101, E303-E322 (2020).

5. Ahmadalipour, A., Moradkhani, H., Castelletti, A. \& Magliocca, N. Sci. Total Environ. 662, 672-686 (2019).

6. IPCC Climate Change 2014: Impacts, Adaptation, and Vulnerability (eds Field, C. B. et al.) (Cambridge Univ. Press, 2014).

7. Schaer, C. Nat. Clim. Change 6, 128-129 (2016).

8. Mora, C. et al. Nat. Clim. Change 7, 501-506 (2017).

9. Li, C., Goswami, Y. \& Stefanakos, E. Renew. Sustain. Energy Rev. 19, 136-163 (2013).

10. Allan, R. P., Soden, B. J., John, V. O., Ingram, W. \& Good, P. Environ. Res. Lett. 5, 025205 (2010).

11. Emanuel, K. A. Nature 436, 686-688 (2005).

12. Palmer, T. N. \& Stevens, B. Proc. Natl Acad. Sci. USA 116 24390-24395 (2019)

13. Eggermont, H. et al. GAIA 24, 243-248 (2015).

14. Seddon, N. et al. Philos. Trans. R. Soc. B 375, 20190120 (2020).

15. Keeler, B. et al. Nat. Sustain. 2, 29-38 (2019).

16. IPBES Global Assessment Report on Biodiversity and Ecosystem Services of the Intergovernmental Science-Policy Platform on Biodiversity and Ecosystem Services (eds Brondizio, E. S. et al.) (2019).

17. Palmer, T. N. Preprint at http://arxiv.org/abs/2007.04830 (2020).

18. Coughlan, E. B. et al. Hydrol. Earth Syst. Sci. 20, 3549-3560 (2016).

19. UNEP The Adaptation Gap Report 2018 (2018).

20. Rozenberg, J. \& Fay, M. Beyond the Gap: How Countries Can Afford the Infrastructure They Need While Protecting the Planet (World Bank, 2019).

Competing interests

The author declares no competing interests. 